\title{
Lower average yields but similar yield variability in organic versus conventional horticulture. A meta-analysis
}

\author{
Claire Lesur-Dumoulin ${ }^{1}$ (D) Eric Malézieux ${ }^{2} \cdot$ Tamara Ben-Ari $^{3} \cdot$ Christian Langlais $^{2}$. \\ David Makowski ${ }^{3}$
}

Accepted: 22 August 2017 / Published online: 23 September 2017

(C) INRA and Springer-Verlag France SAS 2017

\begin{abstract}
Organic agriculture prohibits the use of almost all synthetic inputs and it is expected to have lower impacts on natural resources than conventional agriculture. However, previous meta-analyses have shown that yields in organic systems are in average 8 to $25 \%$ lower compared with conventional systems. Here, we focus on horticulture (fruits and vegetables) and we refine our knowledge by characterising the distributions of organic and conventional yields both in terms of average yield loss and in terms of variability across experiments and across years. We built a new dataset including 636 ratios of organic versus conventional yields covering 37 horticultural species and 17 countries and estimated (i) mean yield ratios, (ii) yield ratio probability distribution across experiments and (iii) interannual yield variances in organic and conventional systems. Our results show that yields in organic horticulture are indeed on average 10 to $32 \%$ lower than those in conventional horticulture but they exhibit large variation across experiments. An analysis of yield ratio probability distribution shows that yield loss in organic horticulture has about $10 \%$ chances to exceed $50 \%$ compared to conventional systems. The analysis gives also around $20 \%$ chances to get higher yields in organic horticulture compared to conventional systems. None of the tested covariates (e.g. crop type, climate zone) was able to explain a significant part of the yield ratio variability. We find no evidence of a larger interannual
\end{abstract}

Claire Lesur-Dumoulin

claire.lesur-dumoulin@inra.fr

DEAR, INRA, Univ Montpellier, 66200 Alénya, France

2 UPR HortSys, CIRAD, 34398 Montpellier, France

3 UMR Agronomie, INRA, AgroParisTech, Université Paris-Saclay, 78850 Thiverval-Grignon, France variability (i.e. lower yield stability) in organic versus conventional horticulture. Longer-term trials could nonetheless help substantiate this result. Our results support also the needs to conduct new experiments in countries from the Southern Hemisphere and to collect standard data on crop management and environmental characteristics.

Keywords Meta-analysis · Organic farming · Organic agriculture · Horticulture · Vegetable · Fruit · Yield ratio . Yield variability

Contents

1. Introduction

2. Material and methods

2.1 Literature search

2.2 Paper selection

2.3 Data extraction

2.4 Organic and conventional yield comparison

2.4.1 Mean yield ratio estimation

2.4.2 Influences of covariates on yield ratios

2.5 Variability of yield ratios across experiments

2.6 Comparison of organic and conventional yield variances across years and across replicates

3. Results and discussion

3.1 Mean ratios of organic to conventional yield and effects of covariates

3.2 Are organic yields generally more variable than conventional ones?

3.2.1. Yield variability across experiments

3.2.2 Yield variability across replicates

3.2.3. Yield variability across years

4. Conclusion

References 


\section{Introduction}

Organic agriculture is becoming of growing importance in the agricultural sector. In 2015, 50.9 million of hectares, i.e. $1.1 \%$ of global agricultural land, were cultivated under organic management compared to 11 million ha in 1999 (Willer and Lernoud 2016, 2017). During the same period, the global organic market size increased about fivefold to reach 81.6 billion US dollars (Willer and Lernoud 2016, 2017). Organic agriculture, which prohibits the use of almost all synthetic inputs, often relies on the intensification of ecological processes (FAO/WHO Codex Alimentarius Commission 1999). Organic management is thus expected to be associated with lower impacts on natural resources than conventional agriculture at the local and global scales (Tuomisto et al. 2012), as well as beneficial effects on human health (e.g. regarding the absence of pesticide residues, Reganold and Wachter 2016) (Fig. 1). However, it also raises concerns regarding its capacity to produce enough food and feed to meet the demand of a wealthier, growing world population (Cassman 2007; Connor 2008, 2013). Consequently, organic to conventional yield gaps are scrutinised (Stanhill 1990; Badgley et al. 2007; de Ponti et al. 2012; Seufert et al. 2012; Ponisio et al. 2015). These studies found yields to be on average 8 to $25 \%$ lower in organic systems with differences depending on the crop species, growing conditions and management practices (Bellon and Lamine, 2009; de Ponti et al. 2012; Seufert et al. 2012). For example, fruits were ranked among the

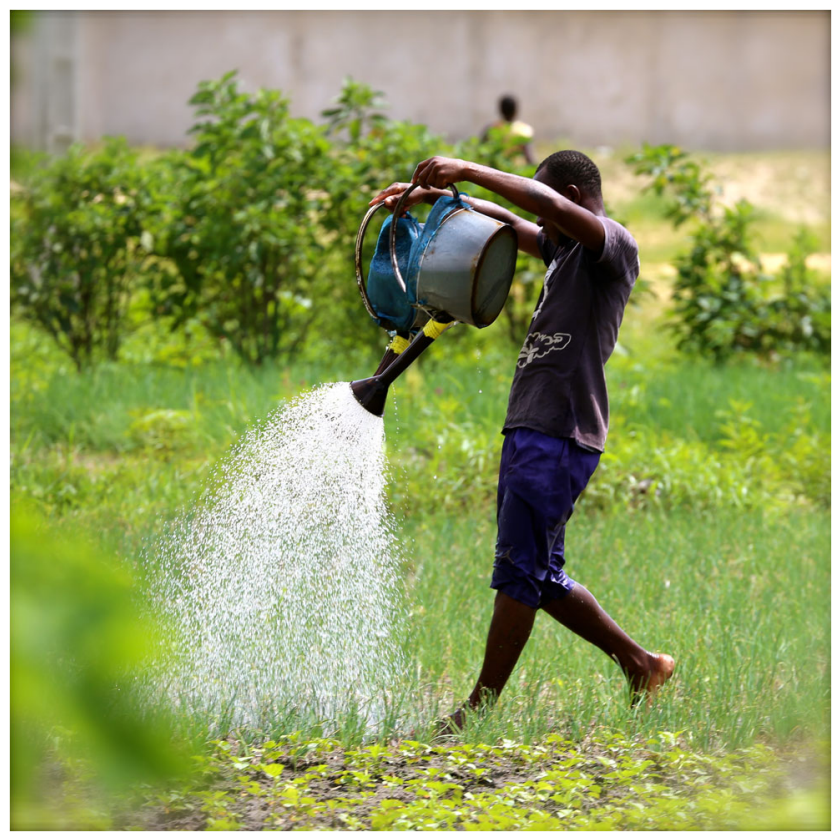

Fig. 1 Vegetable production, here in West Africa, is often associated with the use of high levels of pesticides. The development of organic food chains remains an important challenge in periurban areas and can also be beneficial for farmers' health. Abidjan, Côte d'Ivoire. Photo Eric Malézieux highest yielding crops in organic systems by Seufert et al. (2012) while they were ranked among the lowest by de Ponti et al. (2012). These opposite conclusions may be due to differences in dataset characteristics and in the statistical methods used by the authors (e.g. mixed-effect vs. fixedeffect models, frequentist vs. Bayesian statistical methods). All these studies focused on the average yield difference, but did not analyse variability of yields between sites and between years in organic and conventional management. Some authors have hypothesised that organic farming agroecosystems lead to more stable yields (Altieri 1999; Scialabba and MüllerLindenlauf 2010; Gomiero et al. 2011; Altieri et al. 2015). A few experimental studies indeed reported lower year-to-year variability and lower vulnerability to extreme weather conditions in organic systems (Smolik et al. 1995; Lotter et al. 2003; Smith and Gross 2006). But, others reported larger spatiotemporal variability levels in organic than in conventional agriculture (Smith et al. 2007; Casagrande et al. 2009; Euvard 2010; Delmotte et al. 2011; Rolland et al. 2012). These conflicting results outline that little is known on the relative variability of organic systems compared to conventional ones. This is despite yield variability being a major source of concern for the agri-food system. For example, Cernay et al. (2015) showed that species showing high yield variability tend to be grown on restricted proportions of the cultivated areas. Horticultural producers are particularly risk adverse for at least two motives. First, production costs are high due to a high share of labour costs in low mechanised systems or to substantial fixed costs in soil-less systems (Jeannequin et al. 2011). Second, due to strict marketing standards, biotic and abiotic damages, which can be mitigated using appropriate crop management techniques, generate large wastes associated with high economic losses (as defined by Savary et al. 2006).

In this study, we make progress on the above-mentioned knowledge gaps by performing a meta-analysis on a dataset including the results of 52 papers reporting yield data for 37 horticultural species in 17 countries. We define horticulture as production systems based on vegetables and/or fruit production, both in fields, market gardens or orchards. We compare organic and conventional horticultural crops, analyse average yield differences and assess yield variability across experiments and across years.

\section{Material and methods}

\subsection{Literature search}

A systematic literature review was performed to collect published papers comparing yields in organic versus conventional horticultural crops. We first listed the references mentioned in review papers (Stanhill 1990; Offermann and Nieberg 2000; 
Pretty and Hine 2001; Kaval 2004; Badgley et al. 2007; Seufert et al. 2012). Then, we extended the search using Web of Science with the following equation: « (horticulture* or vegetable* or (tree crop*)) AND organic AND yield* ». The terms in the first bracket were used to select papers dealing with horticultural crops. The other terms were used to select papers dealing with organic farming and reporting yield data. The search equation was applied to the paper titles with no date limit. The references listed in the retrieved articles were also screened. The literature search was completed by November 2014.

\subsection{Paper selection}

An initial selection was made by analysing titles and abstracts. The full texts of the selected papers were then examined. The criteria for selecting the papers were as follows: (1) yield data (or yield ratios) were reported for individual crop species in both organic and conventional treatments; (2) the organic treatment was certified organic, biodynamic or followed organic standards (including in transition to organic horticulture); (3) the reported data were primary data coming from experimental stations or on-farm trials (i.e. farm surveys were not included to avoid confounding effects due to farm characteristics) and were not already reported in other papers; and (4) yield data obtained in organic and conventional treatments were obtained in the same sites during the same time periods. A total of 52 papers met our criteria and were finally selected (Table 2).

\subsection{Data extraction}

Data were extracted from the text, tables and digitised figures of the selected papers and were included in a dataset. Each study was described by the name(s) of the author(s), the year of publication, the type of publication (report, journal, conference, book), the study title, whether the study had already been included in review, and the type of data (experimental, on-farm trial). Each study was related to an experimental site (ES) with each experimental site including one or several comparisons between an organic and a conventional treatment for a given species. If an organic (respectively conventional) treatment was compared in the same experimental site with several conventional (respectively organic) treatments, each comparison was included and hereafter named experimental comparison (EC). For instance, if two conventional $(\mathrm{C} 1, \mathrm{C} 2)$ and two organic $(\mathrm{O} 1, \mathrm{O} 2)$ treatments were tested on the same site, four experimental comparisons were included in the database: $\mathrm{C} 1$ versus $\mathrm{O} 1, \mathrm{C} 2$ versus $\mathrm{O} 1, \mathrm{C} 1$ versus $\mathrm{O} 2$ and $\mathrm{C} 2$ versus $\mathrm{O} 2$. Each experiment can include several years of comparison. In addition to yield data or yield ratios, we also extracted several other characteristics: type of crop (tuber root, vegetable, spice, fruit tree, small fruit, other fruit), crop
Table 1 Scientific names of the crops included in the database

\begin{tabular}{|c|c|}
\hline Latin name & Common name (English) \\
\hline Amorphophallus paeoniifolius & Elephant foot yam \\
\hline Allium сера & Onion \\
\hline Allium porrum & Leeks \\
\hline Allium sativum & Garlic \\
\hline Apium graveolens & Celeriac \\
\hline Asparagus officinalis & Asparagus \\
\hline Beta vulgaris var. flavescens & Chard \\
\hline Beta vulgaris ssp. vulgaris var. conditiva & Beatroot \\
\hline Brassica oleracea & Cabbage (group) \\
\hline Brassica oleracea var botrytis & Cauliflower \\
\hline Brassica oleracea var. capitate & White cabbage \\
\hline Brassica oleracea var. gongylode & Turnip cabbage \\
\hline Brassica oleracea var. sabauda & Savoy cabbage \\
\hline Carthamus & Safflower \\
\hline Cichorium intybus var. foliosum & Endive \\
\hline Citrullus lanatus & Watermelon \\
\hline Citrus latifolia & Tahiti lime \\
\hline Cucumis melo & Melon \\
\hline Cucumis sativus & Cucumber \\
\hline Cucurbita maxima & Pumpkin \\
\hline Cucurbita pepo & Zucchini \\
\hline Daucus carota & Carrot \\
\hline Dioscorea alata & Greater yam \\
\hline Dioscorea esculenta & Lesser yam \\
\hline Dioscorea rotundata & White yam \\
\hline Foeniculum vulgare & Fennel \\
\hline Fragaria $\times$ ananassa & Strawberry \\
\hline Glycine max Merr. & Soya bean \\
\hline Lactuca sativa & Lettuce \\
\hline Malus pumila & Apple \\
\hline Phaseolus vulgaris & Bean \\
\hline Phaseolus vulgaris "type bush" & Bush bean \\
\hline Prunus persica & Peach \\
\hline Solanum lycopersicum & Tomato \\
\hline Solanum tuberosum & Potato \\
\hline Spinacia oleracea & Spinach \\
\hline Vicia faba & Broad bean \\
\hline
\end{tabular}

common name (Table 1), crop scientific name (Table 1), crop life duration (perennial vs. annual crop), legume versus nonlegume crop, type of harvested organ (root, fruit, bulb, leafy), country, climate (tropical, temperate, subtropical, Mediterranean), date, organic type (certified, organic standards, biodynamic, in transition) and conventional type (high input, low input). We refer to low input for conventional treatments using integrated protection methods and/or integrated fertilisation management. 


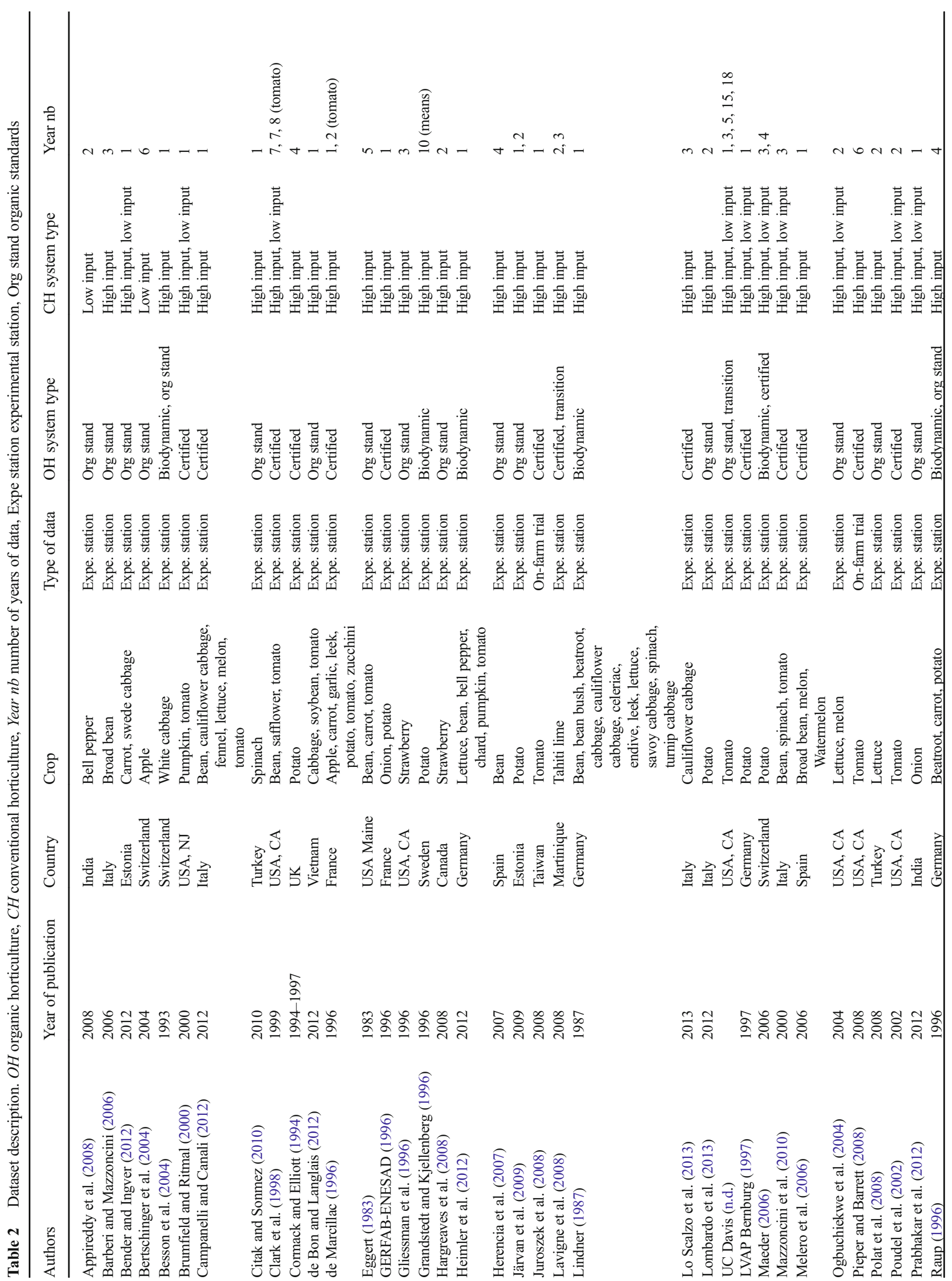


When reported, number of replicates and measure of dispersion (standard deviation, least significant difference, coefficient of variation) were included. Note that organic and conventional treatments sometimes show contrasted cropping practices (e.g. soil tillage, cover crop or crop sequence).

The dataset covers a total of 50 experimental sites, 255 experimental comparisons and 560 yield ratios. Data are obtained for 17 countries and 37 crop species. About two thirds of the data concerns five species: tomato (32\%), apple (10\%), potato $(9 \%)$, spinach $(7 \%)$ and bean $(7 \%)$. About two thirds of the data are obtained from experiments carried out in four European or American countries-the USA (41\%), Italy (8\%), Switzerland (8\%) and Germany (8\%). Four sites locate in Asia and only one in Central America and in Africa.

\subsection{Organic and conventional yield comparison}

\subsubsection{Mean yield ratio estimation}

The natural log of the response ratio was used as an effect size metric for the meta-analysis. An advantage of the ratio metric is that it allows one to handle yield data reported in different units for different crop species. The log transformation is used to normalise data and to ensure positive confidence intervals. The response ratio, $Y$, is calculated as the ratio of organic to conventional yield for each comparison:

$Y=\ln \left(\frac{\overline{X_{\mathrm{O}}}}{\overline{X_{\mathrm{C}}}}\right)$

where $\overline{X_{\mathrm{O}}}$ is the average organic yield calculated over $n_{\mathrm{O}}$ repetitions and $\overline{X_{\mathrm{c}}}$ is the average conventional yields calculated over $n_{\mathrm{C}}$ repetitions.

To account for a possible effect of the choice of a statistical model on the results, eight statistical models are compared to estimate the mean effect size (i.e. the mean yield ratio). This includes two linear fixed-effect models, six linear mixedeffect models including one random effect (random experimental site effect) and two linear mixed-effect models including two random effects (random experimental site and random experimental comparison effects) accounting for the nested structure of the dataset (Table 3). The mixed-effect models 1 and 4 include a random experimental site effect and are defined as follows:

$\ln \left(Y_{i j k}\right)=\mu+b_{i}+\varepsilon_{i j k}$

where $\ln \left(Y_{i j k}\right)$ is the natural $\log$ of the yield ratio in the $i$ th experimental site, the $j$ th experimental comparison and the $k$ th year, $\mu$ is the mean log yield ratio, $b_{i}$ is a random site effect, $b_{i} \sim N\left(0, \sigma_{b}^{2}\right), \varepsilon_{\mathrm{ijk}}$ is the residual error term, $\varepsilon_{\mathrm{ijk}} \sim N\left(0, \sigma_{\varepsilon}^{2}\right)$, and $\sigma_{b}^{2}$ and $\sigma_{\varepsilon}^{2}$ are the between-experiment and within-experiment variances, respectively. The mixed-effect models 2 and 5 are 
based on the same equation but, in these models, the random effect $b_{i}$ describes the variability across experimental comparisons and not across site. The mixed-effect models 3 and 6 include two random effects, one describing the between-site variability and one describing the variability across experimental comparisons. Finally, the fixed-effect models 7 and 8 do not include random effect; they assume that all experiments share the same log yield ratio.

The model parameters are estimated by restricted maximum likelihood using the lme and glm functions from the nlme and stats packages (R v.3.1.2). Models are ranked according to two statistical criteria, the Akaike Information Criterion (AIC) and the Bayesian Information Criterion (BIC). Models 1, 2, 3 and 7 are fitted to the full dataset using unweighted yield ratios. Models 4, 5, 6 and 8 are fitted to a restricted dataset. With this restricted dataset, each yield ratio is weighted using the inverse of the following variance (Hedges et al. 1999):

$\operatorname{var}(Y)=\frac{\mathrm{SD}_{\mathrm{O}}^{2}}{n_{\mathrm{O}} \bar{X}_{\mathrm{O}}^{2}}+\frac{\mathrm{SD}_{\mathrm{C}}^{2}}{n_{\mathrm{C}} \bar{X}_{\mathrm{C}}^{2}}$

where $\mathrm{SD}_{\mathrm{O}}$ and $\mathrm{SD}_{\mathrm{C}}$ are the standard deviation of yield calculated over $n_{\mathrm{O}}$ and $n_{\mathrm{C}}$ replicates in the organic and conventional treatments, respectively. The variance (3) gives more weight to yield ratios computed from a high number of replicates and/or to yield ratios showing a low variability across replicates. The variance defined by (3) could be calculated for 303 out of 560 yield ratios. Values of $\mathrm{SD}_{\mathrm{O}}, \mathrm{SD}_{\mathrm{C}}, n_{\mathrm{O}}$ and $n_{\mathrm{C}}$ are missing for 257 yield ratios. Correlations between experimental comparisons based on the same organic or conventional treatment (i.e. correlations due to multiple organic or conventional treatments on the same siteyears) are not included in our analysis as done in Lajeunesse (2011). However, to take into account the dependency of data collected in the same experimental comparisons, a random effect is included in two of the fitted models (models 3 and 6). Mean yield ratios $\exp (\mu)$ and $95 \%$ confidence intervals are estimated using each model in turn.

Following the best practices recommendations in Philibert et al. (2012), we look for potential publication bias. We compute a funnel plot to relate precision (1/variance of yield ratio, where the variance is computed using (3)) to the natural log of the yield ratio based on the restricted dataset. Its asymmetry is studied considering the estimation of intercept deviation to zero from a regression analysis (Eggert et al. 1997).

\subsubsection{Influences of covariates on yield ratios}

The effects of seven covariates are studied using model 1 (i.e. the best model according to the AIC and BIC criteria): type of crop (fruit tree, small fruit, other fruit, spice, tuber roots, vegetable), type of product (bulb, fruit, leafy, root), annual versus perennial, legume versus non-legume, types of climate
(Mediterranean, subtropical, temperate, tropical), organic system type (biodynamic, certified, organic standards, transition) and conventional system type (high input, low input). Each covariate is included in the model and its statistical significance analysed. Mean yield ratio and confidence intervals are estimated for each level of each covariate. In addition, model 1 is separately fitted to tomato, potato, apple, spinach, bean, lettuce, carrot and onion.

\subsection{Variability of yield ratios across experiments}

According to our statistical models, the probability distribution describing the variability of the log yield ratio across experiments (i.e. across site-years) is a Gaussian distribution with an expected value equal to $\mu$ and a standard deviation equal to $\sigma_{\mathrm{b}}$. The percentiles 1, 5, 50, 95 and $99 \%$ of the yield ratio are computed from the exponential of the corresponding percentiles of the Gaussian distribution.

\subsection{Comparison of organic and conventional yield variances across years and across replicates}

Two types of yield variance are estimated for each experimental comparison: (i) yield variances across repetitions in organic and conventional treatments for experimental comparisons including standard deviations and number of repetitions and (ii) interannual variances of organic and conventional yields for experimental comparisons including at least 5 years of data. Variances (i) describe the yield variability across replicates for a given site-year. Variances (ii) describe the yield variability across years for a given site. Ratios of variances of organic to conventional yields are estimated for each experimental comparison and each variance type, separately. Yield variances are then compared between organic and conventional treatments based on Fisher tests (function var. test, R v.3.1.2, null hypothesis: equality). Finally, we estimate the mean ratio of organic yield standard deviation to conventional yield standard deviation. The individual ratios of yield standard deviations are computed and weighted according to the method described in Nakagawa et al. (2015), for all experimental comparisons including at least 5 years of data. The mean ratio is then estimated using a mixed-effect model including a random experimental site effect.

\section{Results and discussion}

\subsection{Mean ratios of organic to conventional yield and effects of covariates}

The average ratio of organic to conventional yields is equal to 0.83 based on the best model fitted over the total dataset 
(model 1, 95\% confidence interval [0.77-0.90]). Generally, mixed models performed better than fixed-effect models according to both AIC and BIC (Table 3). Model 6, based on the restricted dataset, is also selected and estimates an average ratio of 0.76 (95\% confidence interval [0.68-0.85]). The two best models thus indicate that, across experiments, organic yields are on average at most 10 to $32 \%$ lower than conventional yields. This result is consistent with the three most recent meta-analyses comparing organic versus conventional yields for a large range of species. De Ponti et al. (2012), Seufert et al. (2012) and Ponisio et al. (2015) respectively found organic yields to be on average 20,25 and 19\% lower than conventional yields over all crop species. These authors reported estimated average yield ratios of about $0.8-0.9$ for vegetables and of about $0.72-1$ for fruits. Older studies such as Badgley et al. (2007) and Stanhill (1990) suffered severe methodological impediments: a lack of formal statistical analysis for the former as well as the use of a reduced dataset for the latter. Although a few studies of our dataset with high yield ratios (i.e. $>1$ ) tend to be associated with lower precision levels than the studies displaying yield ratios $<1$, the funnel plot reveals no publication bias (Fig. 2) (i.e. according to the Eggert (1997) test).

Yield ratios do not significantly differ across crop types, product types, biological types (lifespan, nitrogen fixing) and climatic conditions (Fig. 3). Organic horticulture types - certified, organic standards, biodynamic, in transition - and conventional horticulture types - high input and low input-do not show significant effects on yield ratios. For example, the estimated yield ratio is equal to 0.90 (95\% confidence interval $0.75-1.08$ ) for organic systems in transition, and this value is not significantly different from values estimated for certified organic systems ( $p$ value $>0.4$ ). No significant differences are

Table 3 Statistical models used to analyse ratio of organic versus conventional yields. Ime linear mixed-effect model, lfm linear fixedeffect model, $E C$ experimental comparison, $E S$ experimental site. Data were weighted by their variances in models $4,5,6$ and 8 . Italic entries highlight the selected models

\begin{tabular}{lllllll}
\hline $\begin{array}{l}\text { Model } \\
\text { number }\end{array}$ & $\begin{array}{l}\text { Model } \\
\text { type }\end{array}$ & Dataset & $\begin{array}{l}\text { Random } \\
\text { effect }\end{array}$ & Weighting & AIC & BIC \\
\hline 1 & lme & Full (560) & ES & No & 431.5 & 444.5 \\
2 & lme & Full (560) & EC & No & 602.7 & 615.7 \\
3 & lme & Full (560) & ES/EC & No & 433.5 & 450.8 \\
4 & lme & $\begin{array}{c}\text { Subset } \\
(303)\end{array}$ & ES & Yes & 404.1 & 415.2 \\
5 & lme & $\begin{array}{c}\text { Subset } \\
(303)\end{array}$ & EC & Yes & 370.0 & 381.1 \\
6 & lme & $\begin{array}{c}\text { Subset } \\
(303)\end{array}$ & ES/EC & Yes & 213.5 & 228.3 \\
7 & $1 \mathrm{fm}$ & $\begin{array}{c}\text { Full (560) } \\
8\end{array}$ & none & No & 701.6 & 630.5 \\
& \multicolumn{1}{c}{$\begin{array}{c}\text { Subset } \\
(303)\end{array}$} & none & Yes & 326.3 & 333.7 \\
\hline
\end{tabular}

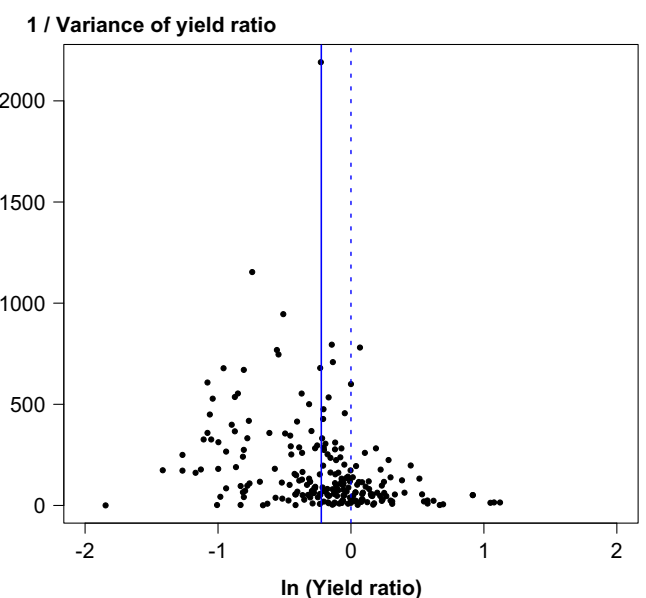

Fig. 2 Funnel plot showing the precision (1/variance of yield ratio) as a function of the natural $\log$ of the organic to conventional yield ratios. Each black circle is the value for any experimental comparisons where standard deviations are informed. Vertical dashed line: 0; vertical full line: $\ln ($ estimated yield ratio)

further found between yield ratios when estimated independently for each crop species (data not shown). Note though that a few crop types (e.g. other and small fruits), product types (e.g. bulb), crop species (e.g. asparagus, celeriac, chard, cucumber) but also some geographical areas (e.g. Africa) are under-represented in our dataset. This reflects the literature but it would be very valuable to extend the geographical coverage of the database with more experiments locating outside Europe or North America. Our results are consistent with Ponisio et al. (2015) who also found no significant differences between crop types, whether defined based on the related food products (cereals, fruits, vegetable, etc.) or on biological traits (legume vs. non-legume crops, perennial vs. annual crops). On the other hand, Badgley et al. (2007), de Ponti et al. (2012) and Seufert et al. (2012) found differences between crop groups but as pointed out by Ponisio et al. (2015) regarding Seufert et al. (2012), statistical methods used in these studies are known to underestimate the sizes of confidence intervals. De Ponti et al. (2012) showed that the yield ratio differed across regions of the world whereas we did not find significant differences between climate types. Note though that our study considers climate, not geographical zones.

As for management, Seufert et al. (2012) reported an effect of irrigation or the use of the best management practices in organic farming on the gap between organic and conventional yields. Ponisio et al. (2015) did not find an effect of management practices at the crop scale but found a diversification of crop species in space or over time to improve yields in organic farming compared to undiversified conventional farming. In our study, the low-input conventional horticulture category refers primarily to level of input use but is also frequently associated to a more diversified crop rotation. In our dataset, the relative effects of input use, rotation diversification or management practices (e.g. tillage, fertilisation, pest management) were generally hard to disentangle. Organic and 


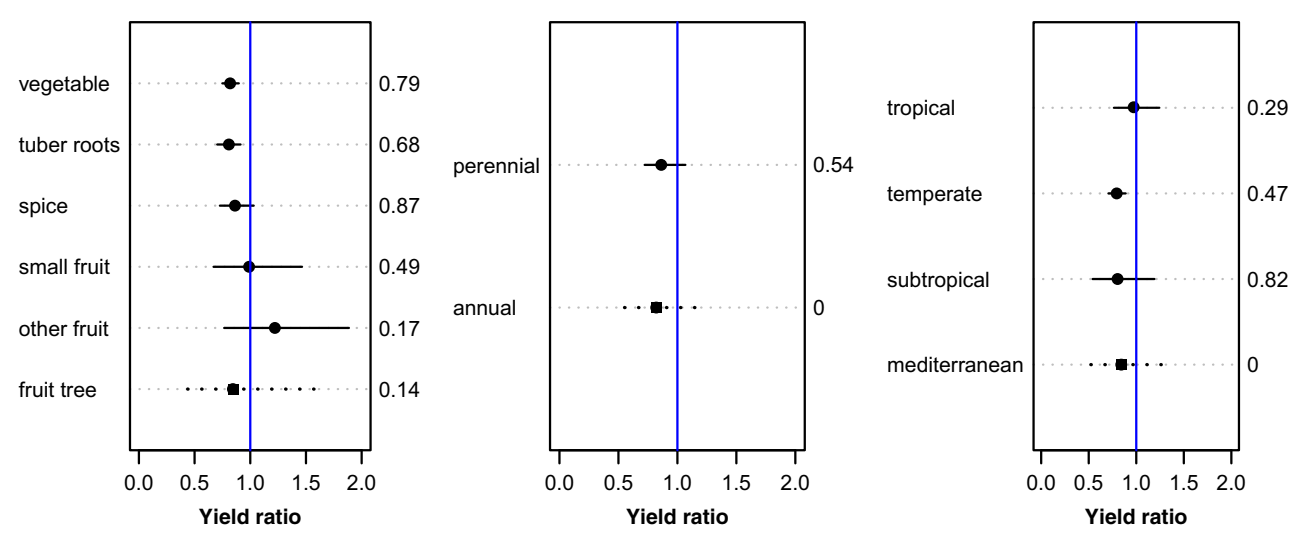

Fig. 3 Effect of crop types and climate conditions on organic to conventional yield ratios for model 1 . For each covariate, one modality is used as reference (black square) and compared to 1 . The other modalities are compared to the reference (i.e. vegetable, tuber roots, spice, small fruit and other fruits are compared to fruit tree; perennial is compared to annual; and tropical. temperate and subtropical are compared to Mediterranean) with corresponding $p$ values indicated on the right side of each graph ( 0 is given for any $p$ value lower than 0.001$)$. Results obtained with model 6 are similar (data not shown). Bars show 95\% confidence intervals; the vertical line indicates a ratio equal to 1 conventional systems cover a diversity of farming systems and a large range of agricultural practices (Sylvander et al. 2006; Darnhofer 2014; Navarrete et al. 2015; Petit and Aubry 2015). Assuredly, progress can be made by an indepth analysis of the effects of management practices on the yield ratio from a detailed description of cropping system characteristics. The yield differences reported here are due to the effect of a differentiated crop management in the same locations. Organic and conventional farms may be located in different physical or economic conditions, as suggested by Seufert and Ramankutty (2017), and differences of location may also have an effect on yields. However, the analysis of this effect is out of the scope for this paper.

\subsection{Are organic yields generally more variable than conventional ones?}

\subsubsection{Yield ratio variability across experiments}

The cumulative probability distribution of the organic to conventional yield ratios reveals large variability across experiments. There is about $90 \%$ chance to get a yield ratio higher than 0.5 ; i.e. yield loss in organic horticulture has a $10 \%$ chance to exceed $50 \%$. On the other hand, organic yields have $50-60 \%$ chances to reach at least $75 \%$ of the conventional yields, and there is a $20 \%$ chance to get higher yields in organic systems. These results highlight that, in horticulture, organic to conventional yield gaps vary greatly across experiments.

Our results reveal the importance of studying both the average yield gap and its variability across experiments. We failed to identify variables significantly explaining the interexperiment variability of yield ratios. Covariates describing in more details the local environment (soil type, weather, pest pressure) and the crop management would be valuable.
Lotter et al. (2003) highlighted for instance that ratios of organic versus conventional maize differed as a function of rainfall. Cooper et al. (2016) showed the interest of dividing reduced tillage practices into different classes to analyse their effect on organic yields. This requires consistent site and management information in published papers.

We can hypothesise that in specific environmental and/or management conditions, organic production is more efficient than conventional production and vice versa. Lotter et al. (2003) showed for instance that organic maize outyields conventional maize in extreme climate conditions. A possible explanation would lie in an improved soil water capture in organic systems related to the use of organic amendments leading to higher soil organic matter.

\subsubsection{Yield variability across replicates}

Based on variance comparison tests, we find that the variances in organic and conventional treatments are significantly different ( $p$ value $<0.01$ ) only in $11 \%$ of the considered experimental comparisons. The variance of the organic treatment was significantly higher than the variance of the conventional treatment in $6 \%$ of the experimental comparisons and lower in $5 \%$. Organic yields are thus generally not more variable across replicates than conventional yields. Kravchenko et al. (2005) highlighted that crop management practices can affect grain yield spatial variability but with alternative impacts according to weather conditions. Although they found no difference in yield spatial variability between low chemical input and conventional treatments, they observed yield variability to be lower in low precipitation years for zero fertiliser input treatment (no chemical inputs nor compost or manure) than in the treatment that received fertiliser inputs. It is however difficult to extrapolate their findings to organic systems. 


\subsubsection{Yield variability across years}

Interannual variability is here analysed based on variance ratio estimated for 36 experimental comparisons including at least 5 years of data (Fig. 4). Although $57 \%$ of the estimated variance ratios are lower than one, none of the variance comparison tests are significant. Over all experimental comparisons including at least 5 years of data, the estimated mean ratio of standard deviations of organic and conventional yields is equal to 0.98 (95\% confidence interval [0.82-1.18]) and is not significantly different from one. This means that, for horticulture, the interannual variability of organic yields is not significantly higher than conventional ones. This result is uncertain; confidence intervals associated with estimated variance ratios are often large because of the relatively small number of data in each experimental comparison. In turn, this large uncertainty partly explains why none of the computed differences are found significant. Our results are consistent with Stanhill (1990) who found no effect of organic farming on the interannual variability of yields. A review of the other papers analysing interannual yield variability suggests

\section{Crop}

tomato

tomato

tomato

tomato

tomato

tomato

tomato

tomato

tomato

tomato

tomato

tomato

tomato

tomato

safflower

safflower

potato

potato

lettuce

lettuce

elephant foot yam

elephant foot yam

carrot

bean

bean

bean

bean

apple

apple

apple

apple

apple

apple

apple

apple

apple

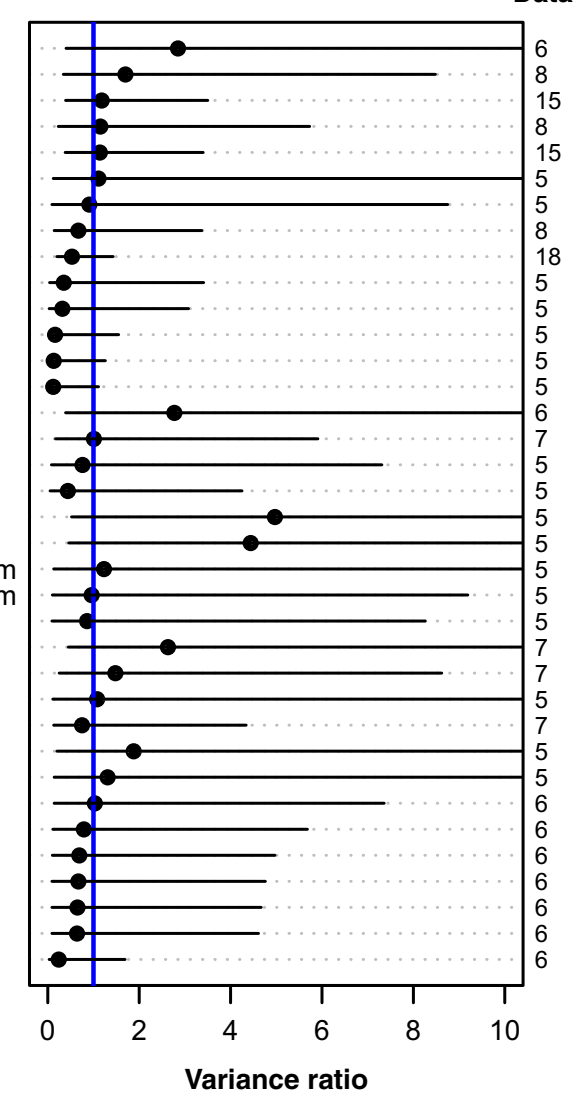

Fig. 4 Ratio of interannual yield variances (organic vs. conventional) estimated for experimental comparisons (EC) including at least 5 years of yield data. Each row corresponds to an EC whose associated crop name is given; the number of years per EC stands on the right. No variance ratio was significantly different from one. The upper bound of the range of variance ratio was set to 10 contrasting results. Comparing different management systems, Smith et al. (2007) showed that interannual yield variability is significantly higher for organic soybean and organic wheat but not for organic corn. Smolik et al. (1995) on the other side reported that year-to-year yield variability is lower in organic systems compared to conventional or reduced-till systems. Lotter et al. (2003) showed that organic maize outyields conventional maize in extreme climate years due to improved soil water capture. Euvard (2010) and Rolland et al. (2012) reported respectively that, in France, organic potato and organic wheat yields are characterised by a high interannual yield variability due to weather or biological fluctuations but did not carry out any comparison with conventional farming. Further research, for example relying on long-term field trials, is therefore needed.

\section{Conclusion}

Our meta-analysis, based on a global comprehensive experimental dataset, shows that yields in organic horticulture are on average 10 to $32 \%$ lower than yields in conventional horticulture. Our analysis reveals a strong variability of organic versus conventional yield ratios across experiments. The probability to get an extremely high yield loss in organic systems is small: yield losses have only $10 \%$ chance to exceed $50 \%$ of conventional yield. On the other hand, organic yields have $20 \%$ chance to exceed conventional yields. These results suggest that, when studying the yield differences between organic and conventional management, agronomists should not only focus on average yield differences but also analyse yield ratio distributions.

We did not identify any covariates significantly affecting the magnitude of yield losses. Our results support the need to further extend the coverage of databases comparing organic versus conventional yield from horticultural crops to (i) better describe crop management to account for the large range of practices existing in organic and in conventional farming systems and (ii) include a description of the local soil and bioclimatic environment.

We find no significant impact on yield ratios of different climatic zones. However, more than $75 \%$ of our dataset is composed of experiments carried out in European or North American countries, whereas these countries cover only $30 \%$ of the organic land dedicated to horticultural crops (Willer and Lernoud 2017). Considering data coming from other regions of the world is therefore crucial.

Our study shows that yield instability is not significantly different in organic versus conventional horticulture. We do not find significant differences between organic and conventional horticulture yield variances across replicates and years. This result is important because high yield variability, which can be perceived as increased risk, may limit the development 
of agricultural activities. The amount of data suitable to analyse interannual yield variability was however limited. A more robust conclusion could be made in the future by analysing new long-term field trials. Other criteria such as the variability of fruit/vegetable nutrient contents (especially in developing countries, as pointed out by Hunter et al. 2011 and Schoonbeek et al. 2013) should also be analysed to assess the costs and benefits of organic products. In addition to criteria related to crop production, organic systems should undoubtedly be compared to conventional systems also according to their environmental and social benefits.

Acknowledgements We are grateful to the two anonymous referees and the editors for their helpful comments. This work was partly funded by the STIMUL (Scenarios towards integrating multi-scale land use tools) flagship project as part of the LabEx BASC (ANR-11-LABX-0034).

\section{References}

Altieri MA (1999) The ecological role of biodiversity in agroecosystems. Agric Ecosyst Environ 74:19-31. https://doi.org/10.1016/S01678809(99)00028-6

Altieri MA, Nicholls CI, Henao A, Lana MA (2015) Agroecology and the design of climate change-resilient farming systems. Agron Sustain Dev 35:869-890. https://doi.org/10.1007/s13593-015-0285-2

Appireddy GK, Saha S, Mina BL et al (2008) Effect of organic manures and integrated nutrient management on yield potential of bell pepper (Capsicum annuum) varieties and on soil properties. Arch Agron Soil Sci 54:127-137. https://doi.org/10.1080/03650340701836808

Badgley C, Moghtader J, Quintero E et al (2007) Organic agriculture and the global food supply. Renewable Agric Food Syst 22:86. https:// doi.org/10.1017/S1742170507001640

Barberi P, Mazzoncini M (2006) The MASCOT (Mediterranean Arable Systems COmparison Trial) long-term experiment (Pisa, Italy). In: Dr. Köster, Raupp J, Pekrun C, Oltmanns M, Köpke U (eds) Longterm field experiments in organic farming. Berlin, Germany, pp 114

Bender I, Ingver A (2012) The influence of production methods on yield and quality of carrots and swedes. Acta Horticulturae. pp 293-298

Bertschinger L, Mouron P, Dolega E, et al (2004) Ecological apple production: a comparison of organic and integrated apple-growing. Acta Horticulturae 321-332. doi: 10.17660/ActaHortic.2004.638. 43

Bellon S, Lamine C (2009) Enjeux et débats actuels sur la conversion à l'AB. In: Transitions vers l'agriculture biologique, Quae, educagri. C.Lamine, S.Bellon (coord.), Versailles, Dijon, France, pp19-50

Besson et al (2004) DOK-Versuch: vergleichende Langzeituntersuchungen in den drei Anbausystemen biologisch-dynamisch, organischbiologisch und konventionell. II. Ertrag der Kulturen: Weiiskohl, 1. Fruchfolgeperiode. Schweizer Landwirtschaft Forschung 32(1/2): 199-218

Brumfield RG, Ritmal A (2000) Comparative cost analyses of conventional, integrated crop management, and organic methods. Horticultural Technology 10:789-793

Campanelli G, Canali S (2012) Production and environmental effects in conventional and organic vegetable farming systems: the case of a long term experiment in Mediterranean conditions (Central Italy). J Sustain Agric 36:599-619

Casagrande M, David C, Valantin-Morison M et al (2009) Factors limiting the grain protein content of organic winter wheat in south- eastern France: a mixed-model approach. Agron Sustain Dev 29: 565-574. https://doi.org/10.1051/agro/2009015

Cassman K (2007) Editorial response by Kenneth Cassman: can organic feed the world - science to the rescue? Renewable Agric Food Syst 22:83-84

Cernay C, Ben-Ari T, Pelzer E et al (2015) Estimating variability in grain legume yields across Europe and the Americas. Sci Rep 5:11171. https://doi.org/10.1038/srep11171

Citak S, Sonmez S (2010) Effects of conventional and organic fertilization on spinach (Spinacea oleracea L.) growth, yield, vitamin C and nitrate concentration during two successive seasons. Sci Hortic 126: 415-420. https://doi.org/10.1016/j.scienta.2010.08.010

Clark MS, Ferris H, Klonsky K et al (1998) Agronomic, economic, and environmental comparison of pest management in conventional and alternative tomato and corn systems in northern California. Agric Ecosyst Environ 68:51-71

Codex Alimentarius Commission, Joint FAO/WHO Food Standards Programme (1999) Guidelines for the production, processing, labelling and marketing of organically produced foods. GL32-1999. Rome, Italy

Connor DJ (2008) Organic agriculture cannot feed the world. Field Crop Res 106:187-190. https://doi.org/10.1016/j.fcr.2007.11.010

Connor DJ (2013) Organically grown crops do not a cropping system make and nor can organic agriculture nearly feed the world. Field Crop Res 144:145-147. https://doi.org/10.1016/j.fcr.2012.12.013

Cooper J, Baranski M, Stewart G et al (2016) Shallow non-inversion tillage in organic farming maintains crop yields and increases soil C stocks: a meta-analysis. Agron Sustain Dev 36:22. https://doi.org/ 10.1007/s13593-016-0354-1

Cormack WF, Elliott J (1994) Organic arable systems at ADDAS Terrington. MAAF Project CSA 3033. Ministry of Agriculture, Fisheries and Food, London (UK)

Darnhofer I (2014) Contributiong to a transition to sustainability of agrifood systems. In: Bellon S, Penvern P (eds) Organic farming, prototypes for sustainable agricultures. Springer, Dordrecht, the Netherlands, pp 439-452

de Bon H, Langlais C (2012) Horticultural organic production in Northern Vietnam: technical or economic questions? In: Acta Horticulturae. Lisboa, Portugal, pp 641-644

de Marcillac (1996) Résultats socioéconomiques en maraîchage biologique

de Ponti T, Rijk B, van Ittersum MK (2012) The crop yield gap between organic and conventional agriculture. Agric Syst 108:1-9. https:// doi.org/10.1016/j.agsy.2011.12.004

Delmotte S, Tittonell P, Mouret J-C et al (2011) On farm assessment of rice yield variability and productivity gaps between organic and conventional cropping systems under Mediterranean climate. Eur J Agron 35:223-236. https://doi.org/10.1016/j.eja.2011.06.006

Eggert FP (1983) Effect of soil management practices on yield and foliar nutrient concentration of dry bean, carrots and tomatoes. In: Locketetz W (ed) Environmental sound agriculture. Fourth international conference of the international federation of organic agriculture movements, Cambridge, Massachusetts, USA, pp 247-259

Eggert M, Davey Smith G, Schneider M, Minder C (1997) Bias in metaanalysis. BMJ:315-629. https://doi.org/10.1136/bmj.315.7109.629

Euvard R (2010) La pomme de terre biologique de plein champ: entre diversité de systèmes et performances technico-économiques Résultats d'enquêtes dans des régions céréalières françaises. Master thesis, AgroCampus Ouest, Arvalis, France

GERFAB-ENESAD (1996) Recherche en production de céréales biologiques: principaux résultats. Groupement d'Etude et de Réalisation dans la Filière de l'Agriculture Biologique, Etablissement National d'Enseignement Supérieur Agronomique de Dijon. Dijon, France 
Gliessman SR, Werner MR, Swezey SL et al (1996) Conversion to organic strawberry management changes ecological processes. Calif Agric 50:24-31. https://doi.org/10.3733/ca.v050n01p24

Gomiero T, Pimentel D, Paoletti MG (2011) Environmental impact of different management pratices: conventional versus organic agriculture. Crit Rev Plant Sci 30(1-2): 95-124. https://doi.org/10.1080/ 07352689.2011 .554497

Grandstedt AG, Kjellenberg L (1996) Quality investigations with the Ktrial, Jarna, and other Scandinavian fertilization experiments. Quality of plant products grown with manure fertilization. Institut for Biodynamic Research, Darmstadt, Germany

Hargreaves JC, Adl MS, Warman PR, Rupasinghe HPV (2008) The effects of organic and conventional nutrient amendments on strawberry cultivation: fruit yield and quality. J Sci Food Agric 88:26692675. https://doi.org/10.1002/jsfa.3388

Hedges LV, Gurevitch J, Curtis PS (1999) The meta-analysis of response ratios in experimental ecology. Ecology 80:1150-1156

Heimler D, Vignolini P, Arfaioli P et al (2012) Conventional, organic and biodynamic farming: differences in polyphenol content and antioxidant activity of Batavia lettuce. J Sci Food Agric 92:551-556. https://doi.org/10.1002/jsfa.4605

Herencia JF, Ruiz-Porras JC, Melero S et al (2007) Comparison between organic and mineral fertilization for soil fertility levels, crop macronutrient concentrations, and yield. Agron J 99:973-983

Hunter D, Foster M, McArthur JO et al (2011) Evaluation of the micronutrient composition of plant foods produced by organic and conventional agricultural methods. Crit Rev Food Sci Nutr 51:571-582. https://doi.org/10.1080/10408391003721701

Järvan M, Edesi L, et al. (2009) The effect of cultivation methods on the yield and biological quality of potato. In: Agronomy research. Estonian University of Life Sciences, Jõgeva Plant Breeding Institute, Estonian Research Institute of Agriculture, pp 289-299

Jeannequin B, Dosba F, Plénet D et al (2011) Vers des cultures fruitières et légumières à hautes performances environnementales. Innov Agronom 12:73-85

Juroszek P, Ledesma D, Ma CH, et al (2008) Plant vigour and yields of organically and conventionally grown tomato crops in Taiwan. In: ISHS Acta Horticulturae 767, pp 257-267. 10.17660/ActaHortic. 2008.767.27

Kaval P (2004) The profitability of alternative cropping systems: a review of the literature. J Sustain Agric 23:47-65. https://doi.org/10.1300/ J064v23n03 06

Kravchenko AN, Robertson GP, Thelen KD, Harwood RR (2005) Management, topographical, and weather effects on spatial variability of crop grain yields. Agron J 97:514-523. https://doi.org/10. 2134/agronj2005.0514

Lajeunesse M (2011) On the meta-analysis of response ratios for studies with correlated and multi-group designs. Ecology 92:2049-2055. https://doi.org/10.1890/11-0423.1

Lavigne C, Pancarte C et al (2008) Faisabilité d'une culture biologique de Lime de Tahiti (Citrus latifolia) à la Martinique. CIRAD Martinique, Lamentin

Lindner U (1987) Eine alternative fur den ewerbgsgemusebau gartenbauliche Versuchsberichte der landwirtshaftkammer Rheinland. Alternativer Anbau 5:106-109

Lo Scalzo R, Picchi V, Migliori CA et al (2013) Variations in the phytochemical contents and antioxidant capacity of organically and conventionally grown Italian cauliflower (Brassica oleracea L. subsp botrytis): results from a three-year field study. J Agric Food Chem 61:10335-10344. https://doi.org/10.1021/jf4026844

Lombardo S, Monaco L, Pandino G et al (2013) The phenology, yield and tuber composition of early crop potatoes. Renewable Agric Food Syst 28:50-58. https://doi.org/10.1017/S1742170511000640

Lotter DW, Seidel R, Liebhardt W (2003) The performance of organic and conventional cropping systems in an extreme climate year. Am J Altern Agric 18:146-154. https://doi.org/10.1079/AJAA200345
LVAP Bernburg (1997) Jahresbericht 1996. Lehr und Versuchsanstalt fur Acker und Pflanzenbau Bernburg. Bernburg, Germany

Maeder P (2006) The DOK experiment (Switzerland). In: Raupp J, Pekrun C, Oltmanns M, Köpke U (eds) ISOFAR, pp 41-58

Mazzoncini M, Canali S, Giovannetti M et al (2010) Comparison of organic and conventional stockless arable systems: a multidisciplinary approach to soil quality evaluation. Appl Soil Ecol 44:124-132. https://doi.org/10.1016/j.apsoil.2009.11.001

Melero S, Porras JCR, Herencia JF, Madejon E (2006) Chemical and biochemical properties in a silty loam soil under conventional and organic management. Soil Tillage Res 90:162-170. https://doi.org/ 10.1016/j.still.2005.08.016

Nakagawa S, Poulin R, Mengersen K et al (2015) Meta-analysis of variation: ecological and evolutionary applications and beyond. Methods Ecol Evol 6:143-152. https://doi.org/10.1111/2041210X.12309

Navarrete M, Dupré L, Lamine C (2015) Crop management, labour organization, and marketing: three key issues for improving sustainability in organic vegetable farming. Int J Agric Sustain. https://doi. org/10.1080/14735903.2014.959341

Offermann F, Nieberg H (2000) Economic performance of organic farms in Europe. In: Dabbert S, Lampkin N, Michelsen J, Nieberg H, Zanoli R (eds) Organic farming in Europe: economics and policy. Stuttgart-Hohenheim, Germany, p 220

Ogbuchiekwe EJ, McGiffen ME, Ngouajio M (2004) Economic return in production of lettuce and cantaloupe is affected by cropping systems and management practice. Hortscience 39:1321-1325

Petit C, Aubry C (2015) Typology of organic management styles in a cash-crop region using a multi-criteria method. Org Agric. https:// doi.org/10.1007/s13165-015-0124-4

Philibert A, Loyce C, Makowski D (2012) Assessment of the quality of meta-analysis in agronomy. Agric Ecosyst Environ 148:72-82. https://doi.org/10.1016/j.agee.2011.12.003

Pieper JR, Barrett DM (2008) Effects of organic and conventional production systems on quality and nutritional parameters of processing tomatoes. J Sci Food Agric 89:177-194. https://doi.org/10.1002/ jsfa. 3437

Polat E, Demir H, Onus AN (2008) Comparison of some yield and quality criteria in organically and conventionally-grown lettuce. Afr J Biotechnol 7(9):1235-1239

Ponisio LC, M'Gonigle LK, Mace KC et al (2015) Diversification practices reduce organic to conventional yield gap. Proc R Soc Lond B Biol Sci 282:20141396. https://doi.org/10.1098/rspb.2014.1396

Poudel DD, Horwath WR, Lanini WT et al (2002) Comparison of soil N availability and leaching potential, crop yields and weeds in organic, low-input and conventional farming systems in northern California. Agric Ecosyst Environ 90:125-137

Prabhakar M, Hebbar SS, Nair AK (2012) Effect of organic farming practices on growth yield and quality of rose onion (Allium cepa). Indian J Agric Sci 82:500-503

Pretty JN, Hine R (2001) Reducing food poverty with sustainable agriculture: a summary of new evidence. University of Essex Colchester

Raup J (1996) Quality investigations with products of the long-term fertilization trial in Darmstadt. Quality of plant products grown with manure fertilization. Institut for Biodynamic Research, Darmstadt

Reeve J, Drost D (2012) Yields and soil quality under transitional organic high tunnel tomatoes. Hortscience 47:38-44

Reganold JP, Wachter JM (2016) Organic agriculture in the twenty-first century. Nat Plants 2:15221. https://doi.org/10.1038/nplants.2015. 221

Reganold JP, Glover J, Andrews P, Hinman H (2001) Sustainability of three apple production systems. Nature 410:926-929

Riahi A, Hdider C, Sanaa M et al (2009) Effect of conventional and organic production systems on the yield and quality of field tomato cultivars grown in Tunisia. J Sci Food Agric 89:2275-2282. https:// doi.org/10.1002/jsfa.3720 
Rolland B, Le Campion A, Oury F-X (2012) Pourquoi sélectionner de nouvelles variétés de blé tendre adaptées à l'agriculture biologique? Le Courrier de l'environnement de l'INRA 62:71-86

Russo VM, Taylor M (2006) Soil amendments in transition to organic vegetable production with comparison to conventional methods: yields and economics. Hortic Sci 41:1576-1586

Savary S, Teng PS, Willocquet L, Nutter FW Jr (2006) Quantification and modeling of crop losses: a review of purposes. Annu Rev Phytopathol 44:89-112. https://doi.org/10.1146/annurev.phyto.44. 070505.143342

Schoonbeek S, Azadi H, Mahmoudi H et al (2013) Organic agriculture and undernourishment in developing countries: main potentials and challenges. Crit Rev Food Sci Nutr 53:917-928. https://doi.org/10. 1080/10408398.2011.573886

Scialabba NEH, Müller-Lindenlauf M (2010) Organic agriculture and climate change. Renewable Agric Food Syst 25(2): 158-169. https://doi.org/10.1017/S174217051000016

Selen D (1993) Economics of organic and conventional horticulture production. University of Guelph, Ontario, Canada

Seufert V, Ramankutty N (2017) Many shades of gray-the contextdependent performance of organic agriculture. Sci Adv 3(3): e1602638. https://doi.org/10.1126/sciadv.1602638

Seufert V, Ramankutty N, Foley JA (2012) Comparing the yields of organic and conventional agriculture. Nature 485:229-232. https:// doi.org/10.1038/nature11069

Simon S, Brun L, Guinaudeau J, Sauphanor B (2011) Pesticide use in current and innovative apple orchard systems. Agron Sustain Dev 31:541-555. https://doi.org/10.1007/s13593-011-0003-7

Smith RG, Gross KL (2006) Weed community and corn yield variability in diverse management systems. Weed Sci 54:106-113. https://doi. org/10.1614/WS-05-108R.1

Smith RG, Menalled FD, Robertson GP (2007) Temporal yield variability under conventional and alternative management systems. Agron J 99:1629. https://doi.org/10.2134/agronj2007.0096

Smolik JD, Dobbs TL, Rickerl DH (1995) The relative sustainability of alternative, conventional, and reduced-till farming systems. Am J Altern Agric 10:25-35. https://doi.org/10.1017/ S0889189300006081

Stanhill G (1990) The comparative productivity of organic agriculture. Agric Ecosyst Environ 30:1-26. https://doi.org/10.1016/01678809(90)90179-H

Suja G, Sundaresan S, John KS et al (2012a) Higher yield, profit and soil quality from organic farming of elephant foot yam. Agron Sustain Dev 32:755-764. https://doi.org/10.1007/s13593-011-0058-5
Suja G, Sreekumar J, John KS, Sundaresan S (2012b) Organic production of tuberous vegetables: agronomic, nutritional and economic benefits. J Root Crops 38:135-141

Swezey SL (1994) Granny Smith conversions to organic show early success. Calif Agric 48:36-44

Sylvander B, Bellon S, Benoit M (2006) Facing the organic reality: the diversity of development models and their consequences on research policies. In: Organic farming and European rural development, Joint Organic Confress. Odense, Denmark

Tabaglio V, Gavazzi C, Nervo G (2008) A comparison of organically and conventionally grown vegetable crops: results from a 4-year experiment. In: 16th IFOAM Organic World Congress. Modena, Italy, p 4

Thorup-Kristensen K, Dresbøll DB, Kristensen HL (2012) Crop yield, root growth, and nutrient dynamics in a conventional and three organic cropping systems with different levels of external inputs and $\mathrm{N}$ re-cycling through fertility building crops. Eur J Agron 37: 66-82. https://doi.org/10.1016/j.eja.2011.11.004

Tuomisto HL, Hodge ID, Riordan P, Macdonald DW (2012) Does organic farming reduce environmental impacts? - a meta-analysis of European research. J Environ Manag 112:309-320. https://doi.org/ 10.1016/j.jenvman.2012.08.018

UC Davis (n.d.) Long Term Reseach on Agricultural Systems (LTRAS). Russel Ranch Sustainable Agricultural Facility, UC Davis, USA

Wang G, Ngouajio M, McGiffen ME, Hutchinson CM (2008) Summer cover crop and in-season management system affect growth and yield of lettuce and cantaloupe. Hortscience 43:1398-1403

Ward JP (n.d.) The Haughley experiment 1952-1965. A summary of the work carried out at the haughley Research Farms and at Dr Milton's laboratory

Warman PR, Havard KA (1997) Yield, vitamin and mineral contents of organically and conventionally grown carrots and cabbage. Agric Ecosyst Environ 61:155-162

Warman PR, Havard KA (1998) Yield, vitamin and mineral contents of organically and conventionally grown potatoes and sweet corn. Agric Ecosyst Environ 61:155-162

Willer H, Lernoud J (eds.) (2016) The world of organic agriculture. Statistics and emerging trends 2016. Research Institute of Organic Agriculture (FiBL), Frick, IFOAM - Organics International, Bonn, Germany

Willer H, Lernoud J (eds.) (2017) The world of organic agriculture. Statistics and emerging trends 2017. Research Institute of Organic Agriculture (FiBL), Frick, IFOAM - Organics International, Bonn, Germany. Version 1.3 of Feb 20, 2017 